\title{
MiRNA-26b inhibits proliferation by targeting PTGS2 in breast cancer
}

\author{
Jia Li ${ }^{\dagger}$, Xiangjie Kong ${ }^{\dagger}$, Junfeng Zhang, Qifeng Luo, Xiaoyu Li and Lin Fang ${ }^{*}$
}

\begin{abstract}
Background: MicroRNAs (miRNAs) are small, non-coding RNAs (20-24 nucleotides) that post-transcriptionally modulate gene expression by negatively regulating the stability or translational efficiency of their target mRNAs. The aim of this study was to investigate the expression pattern of microRNA-26b (miR-26b) in human breast cancer, and its potential role in disease pathogenesis.

Methods: Quantitative reverse transcription-polymerase chain reaction (qRT-PCR) was performed to determine the expression level of miR-26b in 38 breast cancer specimens and adjacent normal breast tissues. MTT assays were conducted to explore the impact of miR-26b overexpression on the proliferation of human MDA-MB-231 breast cancer cells. Luciferase reporter assays were employed to validate regulation of a putative target of miR-26b. The effect of modulating miR-26b on endogenous levels of this target were subsequently confirmed via qRT-PCR and Western blot.
\end{abstract}

Results: MiR-26b expression was relatively decreased in breast cancer specimens compared with adjacent normal tissues $(P<0.01)$. Overexpression of miR-26b suppressed MDA-MB-231 cell growth. Luciferase assays using a reporter carrying a putative miR-26b target site in the $3^{\prime}$ untranslated region of PTGS2 revealed that miR-26b directly targets PTGS2. Overexpression of miR-26b led to downregulation of PTGS2 at the mRNA and protein level, as assessed by qRT-PCR and Western blot. Targeted knockdown of PTGS2 by siRNA significantly inhibited the proliferation of MDA-MB-231 breast cancer cells.

Conclusions: MiR-26b may act as a tumor suppressor in breast cancer. The overexpression of miR-26b inhibits cellular growth by targeting PTGS2, suggesting its use as a potential therapeutic target for breast cancer.

Keywords: MiR-26b, Proliferation, PTGS2, Breast cancer

\section{Introduction}

MicroRNAs are a class of small, non-coding RNAs, which are capable of regulating gene expression at the posttranscriptional level. Mechanistically, miRNAs function by binding to the $3^{\prime}$ untranslated regions (UTRs) of target mRNAs, causing translation to be blocked and/or mRNA degradation [1]. MicroRNAs play diverse roles in tumorigenesis and in the progression of breast cancer, and may act as oncogenes, tumor suppressors and modulators of tumor proliferation, invasion, apoptosis and therapy resistance [2-6]. An increasing body of evidence indicates that miR-26b is downregulated in hepatocellular carcinoma [7], nasopharyngeal carcinoma [8], primary squamous cell lung

\footnotetext{
*Correspondence: fendou000@foxmail.com

${ }^{\dagger}$ Equal contributors

Department of Breast and Thyroid, Shanghai Tenth People's Hospital, Shanghai 200072, China
}

carcinoma [9], squamous cell carcinoma of the tongue [10] and in breast cancer [11]. Furthermore, overexpression of miR-26b induces apoptosis in MCF-7 breast cancer cells by targeting SLC7A11 [11]. However, to date, the role of miR-26b in breast cancer tumorigenesis is incompletely understood.

Prostaglandin-endoperoxide synthase-2 (PTGS2) encodes the COX-2 enzyme, which catalyzes the conversion of arachidonic acid to prostaglandins (PGs) and other eicosanoids. PTGS2 expression, which is undetectable in most normal tissues, is induced in response to hypoxia, inflammatory cytokines, tumor promoters, growth factors and other stressors $[12,13]$. PTGS2 is involved in carcinogenesis, immune response suppression, inhibition of apoptosis, angiogenesis and tumor cell invasion and metastasis. Recent studies have indicated that PTGS2 genetic variation 
is associated with breast cancer susceptibility [14,15]. Furthermore, overexpression of PTGS2 in patients with breast cancer is associated with a worse prognosis [16]. Several studies have demonstrated the involvement of miRNAs in the regulation of PTGS2. MiR-199a and miR101a are implicated in PTGS2 regulation during embryo implantation [17]. Furthermore, miR-26b has been shown to directly silence PTGS2 and regulate PTGS2 expression in desferrioxamine (DFOM)-treated carcinoma of nasopharyngeal epithelial (CNE) cells [8].

In this study, we report that miR-26b expression is significantly decreased in human breast cancer, and its overexpression inhibits the proliferation of MDA-MB-231 cells by targeting PTGS2. These results indicate that miR-26b functions as a tumor suppressor, whose dysregulation may be involved in the initiation and development of human breast cancer.

\section{Results}

\section{Expression of miR-26b is decreased in human breast} cancer

To investigate the involvement of miR-26b in breast cancer development, we analyzed levels of miR-26b in 38 invasive ductal breast cancer tissues and associated normal adjacent tissues (NATs) by quantitative reverse transcriptionpolymerase chain reaction (qRT-PCR). MiR-26b expression was significantly decreased in breast cancer tissues compared with NATs (7.3 fold, $P<0.01$ ) (Figure 1 ).

\section{Suppression of breast cancer proliferation by miR-26b}

To investigate the effect of miR-26b on breast cancer cell proliferation, miR-26b mimics were transfected into the human breast cancer cell line, MDA-MB-231 and proliferation was assessed by MTT assay. As shown in Figure 2, cellular proliferation gradually declined following transfection with miR-26b, in a concentration-dependent

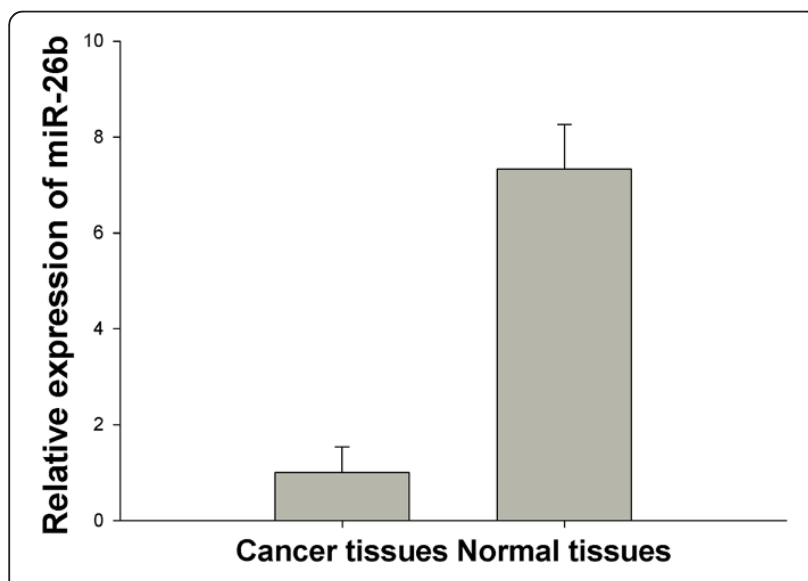

Figure $1 \mathrm{miR}-26 \mathrm{~b}$ is relatively downregulated in breast cancer.

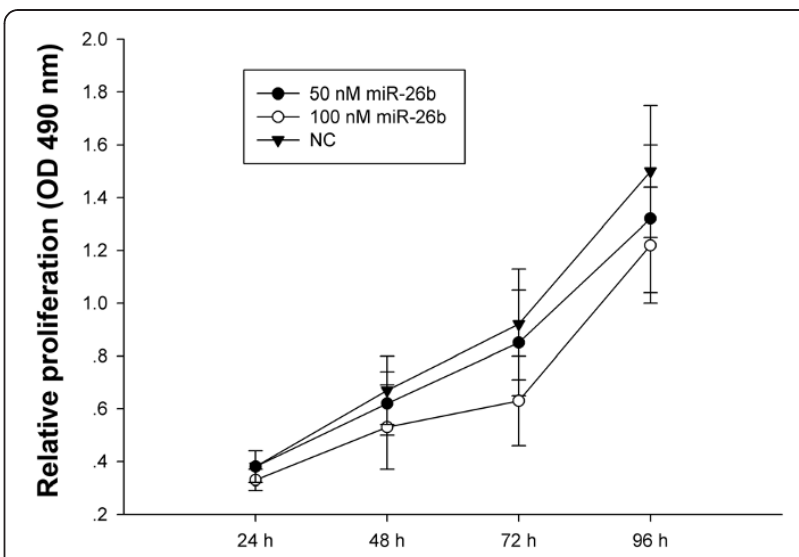

Figure 2 miR-26b inhibits the proliferation of breast cancer cells.

manner. Treatment of cells with $50 \mathrm{nM}$ miR-26b led to a decrease in MDA-MB-231 cell growth at $72 \mathrm{~h}(7 \%)$ and $96 \mathrm{~h}(18 \%)(P<0.05)$ compared with the negative control. This inhibitory effect was significantly enhanced following transfection with $100 \mathrm{nM}$ miR-26b at $48 \mathrm{~h}$ (14\%), $72 \mathrm{~h}$ $(29 \%)$ and $96 \mathrm{~h}(28 \%)(P<0.05)$ compared with the negative control. Taken together, these results demonstrate that miR-26b inhibits the proliferation of MDA-MB-231 breast cancer cells.

MiR-26b regulates PTGS2 expression in breast cancer cells To investigate the downstream targets of miR-26b that may play a role in mediating this growth suppressive effect, we searched for putative targets using the miRanda database. We identified a binding site for miR-26b in the $3^{\prime}$-UTR of PTGS2 mRNA. To validate miR-26b binding to this predicted site, we cloned the 3 '-UTR of PTGS2 containing the putative miR-26b binding site into a luciferase reporter construct, in addition to a mutated PTGS2 3'-UTR (Figure 3A). Luciferase activity was significantly decreased following co-transfection of psiCHECK-2/PTGS2 3'-UTR with miR-26b, compared with the miR-negative control (miR-NC) (Figure 3B). Furthermore, luciferase activity was also decreased following co-transfection of psiCHECK-2 /PTGS2 3'-UTR mutant and miR-26b (Figure 3B). These results indicate that miR-26b specifically binds to the 3'-UTR of PTGS2. The effect of miR-26b transfection on endogenous PTGS2 mRNA and protein expression was subsequently evaluated in MDA-MB-231 cells by qRT-PCR and Western blot. As shown in Figure 3C and $3 \mathrm{D}$, the expression of PTGS2 mRNA and protein was decreased in MDA-MB-231 cells transfected with $100 \mathrm{nM}$ miR-26b mimics compared with the control. These results suggest that miR-26b directly targets PTGS2 in breast cancer cells. 


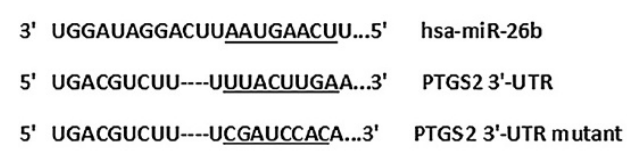

A

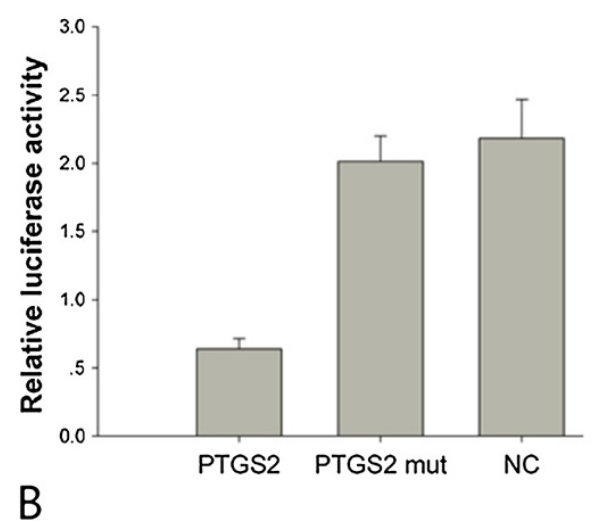

Figure 3 PTGS2 is a direct target of miR-26b in breast cancer.

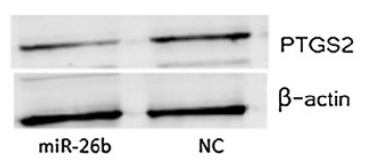

D

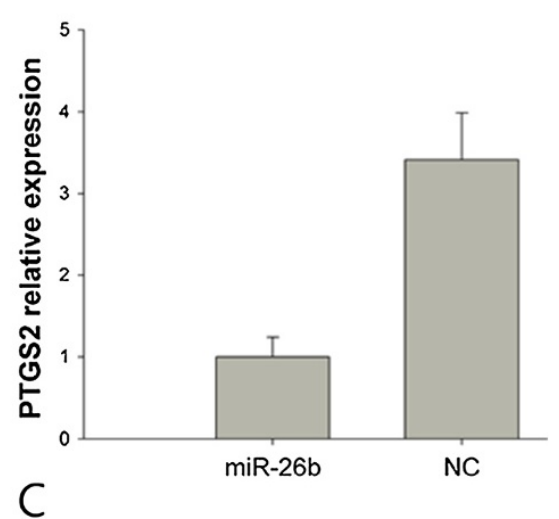

MiR-26b inhibits the proliferation of breast cancer cells via regulation of PTGS2

Since overexpression of miR-26b suppressed the proliferation of MDA-MB-231 breast cancer cells, and given that PTGS2 is a direct target of miR-26b, we hypothesized that the inhibitory effect of miR-26b on breast cancer cell viability might be achieved via targeting PTGS2. To investigate this, we assessed the effect of targeted knockdown of PTGS2 on MDA-MB-231 cell growth by MTT assay. Treatment of cells with $50 \mathrm{nmol} / \mathrm{L}$ PTGS2 siRNA markedly suppressed cell viability by $21 \%, 34 \%$ and $41 \%$ at 48 h, 72 h and 96 h, respectively, compared with control siRNA $(P<0.01)$ (Figure 4$)$. This suggests that
PTGS2 promotes the proliferation of breast cancer cells in vitro. These results demonstrate that downregulation of PTGS2 expression by miR-26b contributes, at least in part, to the suppression of the growth of breast cancer cells.

\section{Discussion}

The discovery of the first miRNA, lin-4, in Caenorhabditis elegans initiated a new era of miRNA biology. Since then, thousands of miRNAs have been identified and annotated. Furthermore, an increasing body of evidence indicates that miRNAs are differentially expressed between normal and tumor tissues, suggesting that dysregulation of miRNA

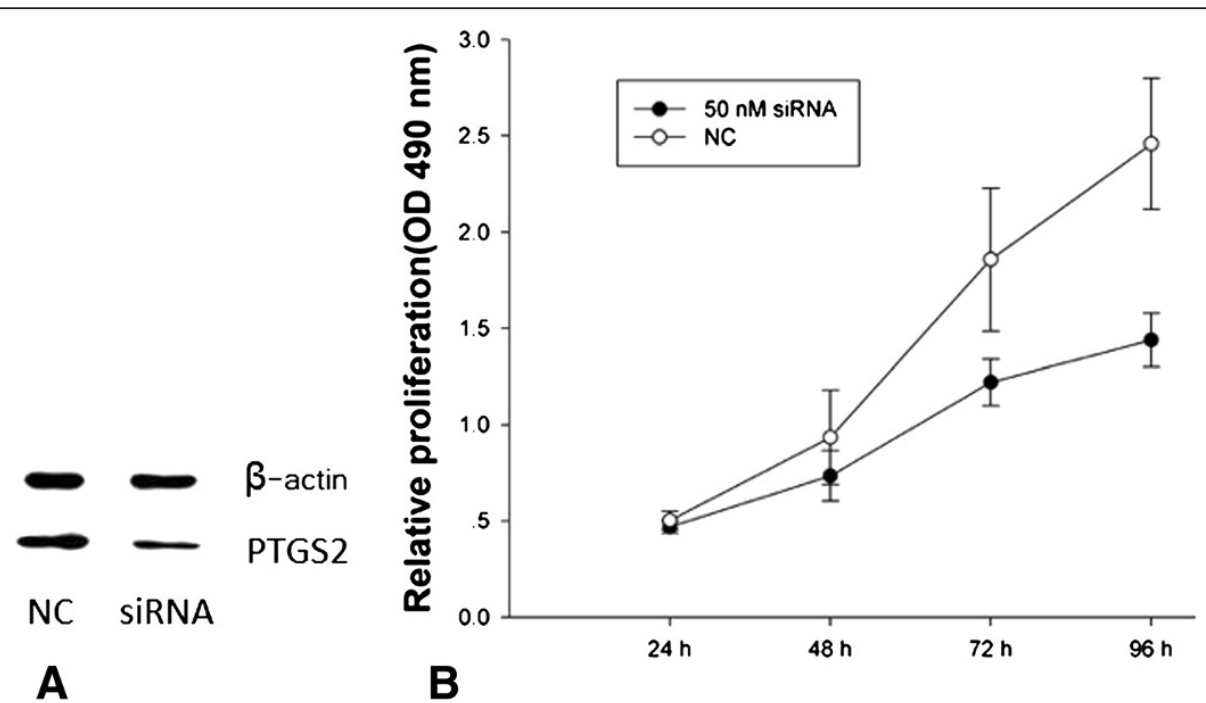

Figure 4 knockdown of PTGS2 significantly supresses the proliferation of breast cancer cells. 
expression is a key factor underlying tumorigenesis [18-22]. In this study, we performed qRT-PCR to investigate the expression pattern of miR-26b in primary human breast cancer. MiR-26b expression was significantly downregulated in breast cancer specimens compared with normal tissue. Similar findings have been reported in several other cancer types, including hepatocellular carcinoma [7], nasopharyngeal carcinoma [8], primary squamous cell lung carcinoma [9], squamous cell carcinoma of tongue [10] and glioma [23]. Consistent with this study, Xiao-Xiao Liu et al. reported that miR-26b expression is downregulated in MCF7, HCC1937, MDA-MB-231, MDA-MB-468, MDA-MB-453, BT-549 and BT-474 breast cancer cell lines compared with CCD-1095Sk normal breast skin cells [11]. These results indicate that miR-26b is downregulated in human breast cancer specimens and cell lines.

It is well established that regulation of gene expression by miRNAs plays a role in the development, differentiation, proliferation, apoptosis, invasion and metastasis of a variety of cancers. In our study, transfection of miR-26b mimics into MDA-MB-231 cells led to a significant decrease in cellular proliferation, indicating that miR-26b represses the growth of breast cancer cells. Previous studies demonstrated that overexpression of miR-26b in DFOMtreated CNE cells inhibited proliferation via degradation of PTGS2 mRNA and suppression of PTGS2 protein translation [8]. Gain- and loss-of-function studies showed that miR-26b and its host genes CTDSP1/2/L cooperate to block $\mathrm{G} 1 / \mathrm{S}$-phase progression by activating pRb protein in hepatocellular carcinoma [24]. MiR-26b is also involved in processes governing apoptosis in breast cancer. Previous studies reported that miR-26b mimics triggered apoptosis of human breast cancer MCF7 cells, and SLC7A11 was identified as a direct target of miR-26b [11]. In glioma, low levels of miR-26b were inversely correlated with tumor grade. Ectopic expression of miR-26b inhibited the proliferation, migration and invasion of human glioma cells, possibly via regulation of its downstream target, EphA2 [23]. Taken together, these studies indicate that dysregulated expression of miR-26b may affect multiple cancers.

Computational algorithms revealed that the $3^{\prime}$-UTR of PTGS2 contains a binding site for miR-26b. To confirm targeting of PTGS2 by miR-26b, we integrated a fragment of the PTGS2 $3^{\prime}$-UTR containing the target sequence, or a fragment whose target site was mutated, into a luciferase reporter vector. Luciferase activity was significantly repressed in cells transfected with the construct harboring the miR-26b target sequence compared with the mutated control vector. Both PTGS2 mRNA and protein levels decreased after transfection of MDA-MB-231 cells with miR-26b, as shown in Figure 3C and 3D. These data indicate that miR-26b directly interacts with
PTGS2 mRNA and represses PTGS2 protein expression. Furthermore, silencing PTGS2 expression by siRNA led to inhibition of cellular proliferation. In conclusion, these findings support the hypothesis that decreased expression of PTGS2 by miR-26b accounts for the suppression of cellular proliferation in breast cancer.

\section{Conclusions}

Taken together, we demonstrate that miR-26b is downregulated in breast cancer specimens compared with normal tissue. MiR-26b directly downregulates PTGS2 and inhibits breast cancer cell proliferation. These data indicate that miR-26b may serve as a tumor suppressor gene involved in breast cancer pathogenesis.

\section{Materials and methods Specimens}

In this study, 38 paired breast cancer and normal specimens were collected from the Department of Breast and Thyroid Surgery of Shanghai Tenth People's Hospital, Shanghai, China. All samples were confirmed as invasive, ductal breast cancer by trained pathologists. No patients received chemotherapy or radiotherapy prior to surgery.

\section{Cell culture}

The MDA-MB-231 breast cancer cell line was purchased from the Chinese Science Institute. Cells were maintained in Dulbecco's Modified Eagle's Medium (DMEM) (Gibco, USA) supplemented with 10\% Fetal Bovine Serum (FBS) (Gibco), penicillin (100 units $/ \mathrm{ml}$ ) and streptomycin $(100 \mu \mathrm{g} / \mathrm{ml})$ (Enpromise, China). Cells were incubated at $37^{\circ} \mathrm{C}$ in a humidified chamber supplemented with $5 \% \mathrm{CO}_{2}$.

\section{qRT-PCR}

For detection of miR-26b expression, primer design and qRT-PCR was performed as previously described [25]. MiRNA was isolated using the miRcute miRNA isolation kit according to the manufacturer's instructions (Tiangen, China). MiR-26b was amplified using the following primers: 5'-GTCGTATCCAGTGCAGGGTCCGAGGTATTCGCA CTGGATACGACGAGCCA-3' (stem-loop primer), 5'-CG CCCTGTTCTCCATTACTT-3' (sense) and 5'-CCAGTGC AGGGTCCGAGGT-3' (antisense). Amplification of control U6 small nuclear RNA was performed using the following primers: $5^{\prime}$-GTCCTATCCAGTGCAGGGT CCGAGGTGCACTGGATACGACAAAATATGGAAC-3' (stem-loop primer), 5'-TGCGGGTGCTCGCTTCGCAGC $-3^{\prime}$ (sense) and $5^{\prime}$-CCAGTGCAGGGTCCGAGGT-3' (antisense). cDNA was generated by reverse transcription using the PrimeScript ${ }^{\mathrm{TM}}$ RT-PCR kit in accordance with manufacturer's instructions (Takara, Japan). Real-time PCR was performed on a 7900HT fast RT-PCR instrument (Applied Biosystems, Singapore). PCR parameters for 
miRNA quantification were as follows: $2 \mathrm{~min}$ at $95^{\circ} \mathrm{C}$, followed by 40 cycles of $30 \mathrm{~s}$ at $95^{\circ} \mathrm{C}$ and $45 \mathrm{~s}$ at $60^{\circ} \mathrm{C}$.

For quantification of PTGS2 mRNA expression, total RNA was isolated using TRIzol (Invitrogen, USA), and cDNA was generated by reverse transcription using the PrimeScript RT-PCR kit in accordance with the manufacturer's instructions (Takara). Real-time PCR was performed on a $7900 \mathrm{HT}$ fast RT-PCR instrument using SYBR-Green and the following primers: PTGS2, $5^{\prime}$-CCTGTGCCTGATGATTGC-3' (sense), $5^{\prime}$-CTGATGC GTGAAGTGCTG- $3^{\prime}$ (antisense); $\beta$-actin, $5^{\prime}$-AGCAGCAT CGCCCCAAAGTT- $3^{\prime}$ (sense) and $5^{\prime}$-GGGCACGAAGGC TCATCATT-3' (antisense). The PCR parameters for relative quantification were as follows: $2 \mathrm{~min}$ at $95^{\circ} \mathrm{C}$, followed by 40 cycles of $15 \mathrm{~s}$ at $95^{\circ} \mathrm{C}$ and $30 \mathrm{~s}$ at $60^{\circ} \mathrm{C}$. Each sample was tested in triplicate. The relative expression was calculated using the relative quantification equation $(\mathrm{RQ})=2-$.Delta; $\Delta \mathrm{CT}[26]$.

\section{Western blot analysis}

Protein samples were separated by $12 \%$ SDSpolyacrylamide gel (SDS-PAGE) and transferred onto PVDF membranes (Beyotime, China). Immune complexes were formed by incubation of membranes with primary antibody (BioVision, USA) overnight at $4^{\circ} \mathrm{C}$. Blots were washed and incubated for $1 \mathrm{~h}$ with HRP-conjugated antirabbit secondary antibody. Immunoreactive protein bands were detected using an Odyssey Scanning system.

\section{MTT assay}

MDA-MB-231 cells (5000/well) were plated in 96-well plates (BD Biosciences, USA) and incubated at $37^{\circ} \mathrm{C}$ overnight. The next day, sub-confluent (50-60\%) cells were transfected with miR-26b mimics $(50 \mathrm{nmol} / \mathrm{L}$ and $100 \mathrm{nmol} / \mathrm{L})$ or PTGS2 siRNA $(50 \mathrm{nmol} / \mathrm{L})$ (Genepharma, China) using Lipofectamine 2000 (Invitrogen, USA), in accordance with the manufacturer's instructions. MiR-NC and siRNA control were used as negative controls. DMEM medium was replaced with DMEM supplemented with $10 \%$ FBS 5 h post-transfection with miR-26b mimics or PTGS2 siRNA. Cell proliferation was assessed at 24, 48, 72 and $96 \mathrm{~h}$, using the MTT proliferation assay kit in accordance with the manufacturer's instructions (Sigma, USA). All experiments were performed in biological triplicate.

\section{Luciferase assay}

The $3^{\prime}$ untranslated region ( $3^{\prime}$ UTR) of PTGS2 containing the predicted miR-26b binding site was amplified by PCR in a total volume of $50 \mu \mathrm{l}$ using the Primer star kit (Takara) in accordance with the manufacturer's instructions. The primers used were $5^{\prime}$-TAGGCGATCGCTCGAGCTGT TGCGGAGAAAGGAGTC-3' (sense); 5'-AATTCCC GGGCTCGAGTAGTTACTTCTAATGCATCATGG-3' (antisense). The mutant constructs were generated by mutation. Fragments were subcloned into the Xho I site in the 3'-UTR of Renilla luciferase of the psiCHECK-2 reporter vector. psiCHECK-2/PTGS2 3 '-UTR or psiCHECK-2 /PTGS-2 3'-UTR mutant reporter plasmids (200 ng) were co-transfected with miR-26b mimics or miR-NC (100 nM) into MDA-MB-231 cells (60\% confluence) using Lipofectamine 2000 (Invitrogen), in accordance with the manufacturer's instructions. After $48 \mathrm{~h}$, cells were lysed and reporter activity was assessed using the Dual-luciferase reporter assay system (Promega, USA) in accordance with the manufacturer's protocols. Renilla luciferase activity was normalized to firefly luciferase activity.

\section{Statistical analysis}

Data are presented as the mean \pm standard deviation from at least three independent experiments. The twotailed $t$-test was used to draw a comparison between groups. The null hypothesis was rejected at the 0.05 level.

\section{Abbreviations}

miRNAs: MicroRNAs; RT-PCR: Quantitative Reverse Transcription-Polymerase Chain Reaction; PTGS2: Prostaglandin-endoperoxide synthase-2; FBS: Fetal bovine serum; DMEM: Dulbecco's modified Eagle's medium; SDS-PAGE: SDSpolyacrylamide gel; NATs: Normal adjacent tissues.

\section{Competing interest}

The authors declare no conflict of interest.

\section{Authors' contributions}

LF designed and directed the study, XK and JZ conducted western blotting, QL and XL performed qRT-PCR, JL performed luciferase reporter assays and drafted the manuscript. All authors read and approved the final manuscript.

\section{Acknowledgments}

This research was made possible with financial support from National Natural Sciences Foundation of China, for the project 81272240, Shanghai Science Committee Foundation (to Lin FANG) (No. STCSM 10411964700).

Received: 11 October 2012 Accepted: 30 January 2013 Published: 1 February 2013

\section{References}

1. He L, Hannon GJ: MicroRNAs: small RNAs with a big role in gene regulation. Nature Rev Genet 2004, 5:522-531.

2. Guttilla IK, White BA: Coordinate regulation of FOXO1 by miR-27a, miR-96, and miR-182 in breast cancer cells. J Biol Chem 2009, 284:23204-23216.

3. Hsu PY, Deatherage DE, Rodriguez BA, Liyanarachchi S, Weng YI, Zuo T, Liu J, Cheng AS, Huang TH: Xenoestrogen-induced epigenetic repression of microRNA-9-3 in breast epithelial cells. Cancer Res 2009, 69:5936-5945.

4. Wu HL, Zhu SM, Mo YY: Suppression of cell growth and invasion by miR205 in breast cancer. Cell Res 2009, 19:439-448.

5. Pan YZ, Morris ME, Yu AM: MicroRNA-328 negatively regulates the expression of breast cancer resistance protein (BCRP/ABCG2) in human cancer cells. Mol Pharmacol 2009, 75:1374-1379.

6. Liang Z, Wu H, Xia J, Li Y, Zhang Y, Huang K, Wagar N, Yoon Y, Cho $H T$, Scala S, Shim H: Involvement of miR-326 in chemotherapy resistance of breast cancer through modulating expression of multidrug resistance-associated protein1. Biochem Pharmacol 2010, 79:817-824

7. Ji J, Shi J, Budhu A, Yu Z, Forgues M, Roessler S, Ambs S, Chen Y, Meltzer PS, Croce CM, Qin LX, Man K, Lo CM, Lee J, Ng IO, Fan J, Tang ZY, Sun HC, 
Wang XW: MicroRNA expression, survival, and response to interferon in liver cancer. N Engl J Med 2009, 361:1437-1447.

8. Ji Y, He Y, Liu L, Zhong X: MiRNA-26b regulates the expression of cyclooxygenase-2 in desferrioxamine-treated CNE cells. FEBS Lett 2010 584:961-967.

9. Gao W, Shen H, Liu L, Xu J, Xu J, Shu Y: MiR-21 overexpression in human primary squamous cell lung carcinoma is associated with poor patient prognosis. J Cancer Res Clin Oncol 2011, 137:557-566.

10. Wong TS, Liu XB, Wong BY, Ng RW, Yuen AP, Wei WI: Mature miR-184 as potential oncogenic microRNA of squamous cell carcinoma of tongue. Clin Cancer Res 2008, 14:2588-2592.

11. Liu XX, Li XJ, Zhang B, Liang YJ, Zhou CX, Cao DX, He M, Chen GQ, He JR, Zhao Q: MicroRNA-26b is underexpressed in human breast cancer and induces cell apoptosis by targetingSLC7A11. FEBS Lett 2011, 585:1363-1367.

12. Schmedtje JF Jr, Ji YS, Liu WL, DuBois RN, Runge MS: Hypoxia induces cyclooxygenase-2 via the NF-kappaB p65 transcription factor in human vascular endothelial cells. J Biol Chem 1997, 272:601-608.

13. Liu XH, Kirschenbaum A, Yao S, Stearns ME, Holland JF, Claffey K, Levine AC: Upregulation of vascular endothelial growth factor by cobalt chloridesimulated hypoxia is mediated by persistent induction of cyclooxygenase-2 in a metastatic human prostate cancer cell line. Clin Exp Metastasis 1999, 17:687-694.

14. Dossus L, Kaaks R, Canzian F, Albanes D, Berndt Sl, Boeing H, Buring J, Chanock SJ, Clavel-Chapelon F, Feigelson HS, Gaziano JM, Giovannucci E, Gonzalez C, Haiman CA, Hallmans G, Hankinson SE, Hayes RB, Henderson BE, Hoover RN, Hunter DJ, Khaw KT, Kolonel LN, Kraft P, Ma J, Le Marchand L, Lund E, Peeters PH, Stampfer M, Stram DO, Thomas G, et al: PTGS2 and IL6 genetic variation and risk of breast and prostate cancer: results from the Breast and Prostate Cancer Cohort Consortium (BPC3). Carcinogenesis 2010, 31:455-461.

15. Langsenlehner U, Yazdani-Biuki B, Eder T, Renner W, Wascher TC, Paulweber B, Weitzer W, Samonigg H, Krippl P: The cyclooxygenase-2 (PTGS2) 8473T $>$ C polymorphism is associated with breast cancer risk. Clin Cancer Res 2006, 12:1392-1394.

16. Festa-Vasconcellos JS, Piranda DN, Amaral LM, Indio-do-Brasil V, Koifman S, Vianna-Jorge R: Polymorphisms in cycloxygenase-2 gene and breast cancer prognosis: association between PTGS2 haplotypes and histopathological features. Breast Cancer Res Treat 2012, 132:251-258.

17. Chakrabarty A, Tranguch S, Daikoku T, Jensen K, Furneaux H, Dey SK: MicroRNA regulation of cyclooxygenase-2 during embryo implantation. Proc Natl Acad Sci USA 2007, 104:15144-15149.

18. Iorio MV, Ferracin M, Liu CG, Veronese A, Spizzo R, Sabbioni S, Magri E, Pedriali M, Fabbri M, Campiglio M, Ménard S, Palazzo JP, Rosenberg A, Musiani P, Volinia S, Nenci I, Calin GA, Querzoli P, Negrini M, Croce CM: MicroRNA gene expression deregulation in human breast cancer. Cancer Res 2005, 65:7065-7070.

19. Yan LX, Huang XF, Shao Q, Huang MY, Deng L, Wu QL, Zeng YX, Shao JY: MicroRNA miR-21 overexpression in human breast cancer is associated with advanced clinical stage, lymph node metastasis and patient poor prognosis. RNA 2008, 14:2348-2360.

20. Ji Q, Hao X, Meng Y, Zhang M, Desano J, Fan D, Xu L: Restoration of tumor suppressor miR-34 inhibits human p53-mutant gastric cancer tumor spheres. BMC Cancer 2008, 8:266.

21. Nagel R, le Sage C, Diosdado B, van der Waal M, Oude Vrielink JA, Bolijn A, Meijer GA, Agami R: Regulation of the adenomatous polyposiscoli gene by the miR-135 family in colorectal cancer. Cancer Res 2008, 68:5795-5802.

22. Liu W, Gong YH, Chao TF, Peng XZ, Yuan JG, Ma ZY, Jia G, Zhao JZ: Identification of differentially expressed microRNAs by microarray: a possible role for microRNAs gene in medulloblastomas. Chin Med J (Engl) 2009, 122:2405-2411.

23. Wu N, Zhao X, Liu M, Liu H, Yao W, Zhang Y, Cao S, Lin X: Role of microRNA-26b in glioma development and its mediated regulation on EphA2. Plos One 2011, 6:e16264.

24. Zhu Y, Lu Y, Zhang Q, Liu JJ, Li TJ, Yang JR, Zeng C, Zhuang SM: MicroRNA-26a/b and their host genes cooperate to inhibit the G1/S transition by activating the pRb protein. Nucleic Acids Res 2012, 40:4615-4625.
25. Chen C, Ridzon DA, Broomer AJ, Zhou Z, Lee DH, Nguyen JT, Barbisin M, Xu NL, Mahuvakar VR, Andersen MR, Lao KQ, Livak KJ, Guegler KJ: Real-time quantification of microRNAs by stem-loop RT-PCR. Nucleic Acids Res 2005, 33:e179.

26. Livak KJ, Schmittgen TD: Analysis of relative gene expression data using Real-time quantitative PCR and the $2^{-\Delta \Delta c t}$ method. Methods 2001, 25:402-408

doi:10.1186/1475-2867-13-7

Cite this article as: Li et al:: MiRNA-26b inhibits proliferation by targeting PTGS2 in breast cancer. Cancer Cell International 2013 13:7.

\section{Submit your next manuscript to BioMed Central and take full advantage of:}

- Convenient online submission

- Thorough peer review

- No space constraints or color figure charges

- Immediate publication on acceptance

- Inclusion in PubMed, CAS, Scopus and Google Scholar

- Research which is freely available for redistribution 